\title{
Inventor Moral Hazard in University Licensing: The Role of Contracts
}

\author{
Emmanuel Dechenaux \\ Jerry Thursby \\ Kent State University Georgia Institute of Technology \\ Marie Thursby \\ Georgia Institute of Technology and NBER
}

April 29, 2008

\begin{abstract}
We examine commonly observed forms of payment, such as milestones, royalties, or consulting contracts as ways of engaging inventors in the development of licensed inventions. We show that when milestones are feasible, royalties are not optimal unless the licensing firm is risk averse. The model also predicts the use of consulting contracts which improve the firm's ability to monitor inventor effort. Because these contracts increase the firm's expected profits, the upfront fee that the university can charge is higher than otherwise. These results therefore support the commonly observed university policy of allowing faculty to consult with licensing firms outside of their university contracts. They also support firm policies of including milestones. An empirical analysis based on a survey of 112 businesses that license-in university inventions supports the complementarity of milestones and consulting suggested by the theory.
\end{abstract}

J.E.L. codes: D82, L14, O3

Keywords: University licensing, Milestone payments, Consulting, Bayh-Dole Act

\section{Introduction}

University-generated knowledge is critical to industrial innovation, but the transfer of this knowledge is fraught with incentive problems, largely because of the embryonic nature of university inventions (Dechenaux et al. 2008 and Thursby and Thursby 2008). The overwhelming majority of inventions licensed require further development 
which often requires inventor effort as well as licensee investment. In their survey of 62 US universities, Thursby et al. (2001) found that half of the inventions licensed were merely a proof of concept and another $25 \%$ were no more than a lab scale prototype. Moreover, technology licensing personnel estimated that $71 \%$ of the inventions required inventor cooperation in order to be successfully commercialized. ${ }^{1}$ In this paper we focus on the role of license contracts in solving the moral hazard problem that arises when inventor cooperation is important for development.

Faculty inventors are motivated to work for both pecuniary and non-pecuniary reasons. While they care about income, their research is also often curiosity driven and therefore motivated by the love of puzzle solving as well as a desire for reputation (Dasgupta and David 1994, Levin and Stephan 1991, and Thursby et al. 2007). Thus, to the extent that faculty inventors prefer to solve new puzzles rather than develop existing inventions, obtaining cooperation requires financial incentives tied to development. Recent studies have examined these incentives in the context of royalties or equity contracts (Jensen and Thursby 2002 and Lach and Schankerman 2008).

In this paper, we examine the extent to which commonly observed forms of payment, such as milestones, or consulting contracts dominate royalties as a means of engaging inventors in development. In contrast to prior studies which examine the problem from the perspective of the university, we examine desired forms of payment from the licensing firm's perspective. We also provide an empirical analysis based on a survey of 112 businesses that license-in university inventions. The survey explored the types of inventions licensed, the need for inventor cooperation in development, and the importance of contract types for various kinds of inventions. The survey showed that contracts typically involve a mixture of payment types including royalties and milestones, and when inventor cooperation is critical to development, the majority of licenses include additional consulting contracts.

We first construct a model of university licensing which allows us to develop hypotheses about the use of milestones, royalties, and consulting. As do Dechenaux et al. (2008) in a different context, we find that when milestones are feasible, royalties can be optimal only when the licensee is risk averse. The reason is that, while royalties provide an incentive for inventor effort, they also distort output, while milestones do not. Importantly for the empirical analysis, we also show that milestone payments are positively related to the importance of inventor effort in the development process. The model also predicts that consulting contracts will be used to engage the inventor when such contracts sufficiently improve the firm's ability to monitor inventor effort. Because these contracts increase the firm's expected profits, the upfront fee that the university

\footnotetext{
${ }^{1}$ For when inventor involvement is and is not used see Colyvas et al. (2002), Thursby and Thursby (2004 and 2008), and Agrawal (2006).
} 
can charge is higher than otherwise. These results therefore support the commonly observed university policy of allowing faculty to consult with licensing firms outside of their university contracts. They also support firm policies of including milestones.

In the empirical analysis, we examine survey responses to a series of questions on the use of different payment types for early and late stage inventions, as well as when inventor cooperation is and is not critical. Analysis of these responses shows that milestones are perceived to be most important for assuring inventor cooperation, while also playing a secondary role in risk sharing. Royalties do not appear to be used to address moral hazard, nor are they significantly more prevalent for the more risky, early-stage inventions. We conjecture that their risk sharing role is mitigated by difficulties in defining them for early stage inventions. The survey also includes data on consulting contracts in relation to the need for inventor cooperation. Our analysis of these data support the complementarity of milestones and consulting suggested by the theory.

These results contribute to the theoretical literature on the role of faculty inventors in technology commercialization, which has primarily focused on simple contracts. Jensen and Thursby (2001) showed that without either royalties or equity, faculty inventors who prefer research to development would not become engaged. They also show that inventor effort is increasing in the inventor's share of royalty payments made to the university. ${ }^{2}$ Dechenaux et al. (2008) examines the use of a variety of payment types, including not only milestones, but also annual payments, royalties, and upfront fees. They do not examine consulting, but more importantly, their analysis focuses primarily on the complicated nature of contracts when shelving by the licensee is a problem, which we do not address here.

Very few studies, either empirical or theoretical, consider consulting. Notable exceptions include Mansfield (1995) and Cohen et al. (1998) who provide survey evidence that both faculty and industry personnel find technology transfer by this mechanism to be important. Beath et al. (2003) provide a theoretical analysis of the potential for budget-constrained universities to relax the constraint by encouraging faculty to consult. The work closest to ours is Thursby et al. (2007) and Jensen et al. (2008) which examine consulting as a mechanism behind faculty inventors listed on industrial patents. Jensen et. al. (2008) provide a theoretical model that examines the trade-off between faculty consulting on industrial research projects and their research within their university. The primary difference between their work and ours is that we consider ex post development on a project licensed from the university, while they examine consulting that is ex ante research by a faculty member on an industrial project.

\footnotetext{
${ }^{2}$ For empirical studies on the relation between royalty shares, royalty income, and faculty behavior see Lach and Schankerman (2008) and Agrawal (2006). On equity, see also Feldman et.al. (2002).
} 
We also contribute to the empirical licensing literature which has, like the theoretical literature, focused primarily on fixed fees and royalties (Taylor and Silberston 1973, Caves et al. 1983, Rostoker 1983, Macho-Stadler et al. 1996, and Bousquet et al. 1998). An exception is Edwards et al. (2003) which provides evidence on the frequency of milestones and other fees in biotechnology licenses. With the exception of Arora et al. (2001), Anand and Khanna (2000), and Elfenbein (2004), few studies provide econometric models. ${ }^{3}$ The study closest to ours is Elfenbein's which examines the likelihood of termination of licenses for Harvard inventions as a function of royalties and milestone payments. His analysis differs substantially from ours as it is purely empirical and abstracts from the role of different distortions in explaining the use of royalties and milestones.

Section 2 provides survey results to motivate our consideration of multiple development stages as well as our characterization of risk and the need for inventor cooperation in development. Section 3 develops a simple model of contracts as a function of inventor cooperation and risk. In Section 4 we test several implications of the model using survey responses on the importance of contract terms with and without the need for inventor cooperations, as well as for early and late stage inventions. Section 5 concludes.

\section{Stage of development and faculty participation}

Our business survey largely agrees with earlier university surveys in showing the embryonic nature of university inventions licensed, but it also provides more information on the relation between stage of development, risk, and faculty participation. As shown in Table 1, our respondents estimated that $38 \%$ of the inventions they licensed were no more than a proof of concept, and an additional $36 \%$ no more than a lab-scale prototype at the time of license. They reported knowing manufacturing feasibility for only $9 \%$ of the inventions. No more than $7 \%$ were considered ready for commercial use, so that at least $93 \%$ of the inventions licensed required further development by the licensee.

We asked respondents the percentage of time that faculty were involved in further development for licensed inventions in different stages of development. For technologies that were only a proof of concept, respondents indicated that faculty were used 55 percent of the time. Faculty were used for 54 percent for technologies for which a

\footnotetext{
${ }^{3}$ Arora examines the complementarity of know-how transferred and patent rights for import agreements in India from 1950-75, but does not examine license payment terms. Anand and Khanna examine license contracts from a data base of strategic alliances with at least one US participant from 1990-93. The characteristics they examine include exclusivity, cross-licensing, ex ante versus ex post transfer, and prior relationships of licensors and licensees.
} 


\begin{tabular}{|l|c|c|}
\hline $\begin{array}{l}\text { Stage } \\
\text { of development }\end{array}$ & $\begin{array}{c}\text { Percentage } \\
\text { of cases }\end{array}$ & $\begin{array}{c}\text { Faculty } \\
\text { involvement }\end{array}$ \\
\hline Proof of concept (no prototype) & $38 \%$ & $55 \%$ \\
\hline Prototype (only lab scale) & $36 \%$ & $54 \%$ \\
\hline Preclinical stage & $15 \%$ & $38 \%$ \\
\hline Clinical stage & $5 \%$ & $18 \%$ \\
\hline Manufacturing feasibility known & $9 \%$ & $15 \%$ \\
\hline Ready for practical or commercial use & $7 \%$ & $15 \%$ \\
\hline
\end{tabular}

Table 1: Stage of development at the time of license and faculty involvement at that stage.

laboratory-scale prototype was available. If the technology was either ready for use or its manufacturing feasibility was known, faculty were involved only 15 percent of the time. When faculty were considered important for further development, respondents were asked why this was the case. Not surprisingly, specialized knowledge of faculty inventors was given as the most important reason, cited by 66 percent of respondents.

This development is clearly risky. Respondents reported that roughly half of the inventions they license from universities failed in the sense that the technology did not fit the need anticipated at the time of license. The average failure rate reported for inventions licensed as a proof of concept or lab-scale prototype was $72 \%$, while the average for inventions ready for commercial use was $43 \% .^{4}$ The correlation between the reported failure rate and the fraction of licenses that are a proof of concept is .31, while the correlation of the failure rate with the fraction ready for commercial use is -.23 .

\section{A model of university licensing}

Consider a university invention which is available for license from a university technology licensing office (TLO). The invention requires further development before it can be commercialized. There are two stages of development, both of which are characterized by uncertainty. In the first stage, inventor effort and firm investment are needed to determine technical success of the invention, and in the second stage, the firm invests in commercialization. The timing of events is shown in Figure 1.

The probability of technical success is given by $p(e, x)$ where $e$ is inventor effort

\footnotetext{
${ }^{4}$ The mean reported was the mean percentage weighted by the number of license deals.
} 
and $x$ is the firm's investment. We assume the following

$$
p(e, x)= \begin{cases}0 & \text { if } x=0 \text { and } e \geq 0 \\ p(1-b \exp (-e)) & \text { if } x=X \text { and } e \geq 0\end{cases}
$$

where $p \in(0,1]$ and $b \in[0,1]$. The probability $p(e, x)$ is increasing in both arguments and strictly concave as a function of $e$. The parameter $b$ measures the importance of the inventor's role in the development process. When $b$ is equal to zero, the probability of success depends solely on the firm's investment and is equal to $p$ if $x=X$ and zero otherwise. Hence, if $b$ is equal to one, then $e=0$ implies $p(0, X)=0$. That is, inventor effort is necessary for a positive probability of technical success. The parameter $p$ can be interpreted as a measure of the risk involved in developing the invention. As $p$ goes to zero, even if $x=X$, the probability of success goes to zero for any given level of inventor effort. Early stage inventions are those with a low $p$ and possibly a large $b$. On the other hand, a late stage invention is one for which $p$ is close to one and $b$ is close to zero. If the invention is a technical success, the project moves to the commercial development stage. The firm may invest an amount $C$ in commercial development. If the firm invests, the probability of commercial success is equal to $z$. Otherwise, the invention is not commercialized.

The university owns and can exclusively license the invention and the TLO acts on behalf of the university. We assume that the TLO maximizes expected utility given by $E U_{A}=(1-\alpha) \tilde{R}$, where $(1-\alpha)$ is the share of revenue that accrues to the university or TLO and $\tilde{R}$ is the expected value of licensing revenue. ${ }^{5}$

The inventor's utility from license revenue is given by $U_{I}(\tilde{R})=\alpha \tilde{R}$. She incurs strictly positive and increasing disutility of effort represented by the function $V(e)=$ $\exp (e)$.

The TLO offers the firm an exclusive license contract that specifies all payment terms. We denote a contract by $O=(F, M, r, t)$. We restrict attention to the following payment types. Payment term $F$ is an upfront fee paid when the firm accepts the contract. Payment term $M$, which we refer to as a milestone payment, is a lump sum fee paid if and only if technical development is successful. Finally, $r$ is an output royalty, and $t$ is a profit tax or alternatively, a share of the firm's equity. ${ }^{6}$ Hereafter,

\footnotetext{
${ }^{5}$ In order to focus on the moral hazard problem, we abstract from any agency problems with the TLO and university, as well as multiple objectives on the part of either the university or TLO. See Thursby et al. (2001), and Dechenaux et al. (2008) regarding other objectives.

${ }^{6}$ Note that Jensen and Thursby (2001) also consider $F, r$, and $t$. Bousquet et al. (1998) consider upfront fees and royalties only. However, they allow for two different types of royalties. One is an output royalty, and the other is a tax on the firm's revenue. We focus on output royalties, which is without loss of generality in our model. Either type of royalty implies a distortion of the licensee's output, which is what matters for our results. Because of the way we model uncertainty at the
} 
we refer to $M, r$ and $t$ as continuation payments, since the firm would have to return the license if it failed to make any of these payments.

The firm's expected utility is given by its expected profit net of license payments. The firm's profit from selling a product based on the invention is equal to $\pi(x)$ with $x$ denoting output. Where there is no ambiguity, we write $\pi$ for $\max _{x}\{\pi(x)\}$. Clearly, in the absence of distortionary payments based on output, if the firm commercializes the invention, it chooses the optimal level of output and earns $\pi$. Thus, immediately after technical success, the firm's expected profit is given by $\Pi\left[x^{*}(r, t), r, t\right]=\max \{z[(1-$ $\left.\left.t) \pi\left[x^{*}(r, t)\right]-r x^{*}(r, t)\right]-C, 0\right\}$, where $x^{*}(r, t)$ is the firm's optimal output level when the royalty rate is $r>0$ and the equity share is equal to $t$. If the firm invests $X$ at the technical development stage, and behaves optimally at the commercialization stage, its expected payoff is given by

$$
p(e, X)\left[\Pi\left[x^{*}(r, t), r, t\right]-M\right]-X-F \text {. }
$$

As other studies have shown in different contexts, when inventor effort is not observable, continuation payments are required to obtain positive effort from the inventor (Dechenaux et al., 2008; Thursby et al., 2005; Choi, 2001; Jensen and Thursby, 2001; Macho-Stadler et al., 1996). Moreover, with risk neutrality, an output royalty is not optimal because it creates a deadweight loss, which the TLO could avoid by using other payment types. Finally, when the inventor is risk neutral, upfront fees do not affect his optimal level of effort (Jensen and Thursby, 2001). Hence, for most of the analysis below, we focus on continuation payments that exclude output royalties.

There are different ways to model the contract offer game between the TLO and the firm. For instance, we could follow Jensen and Thursby (2001) and Dechenaux et al. (2008) and assume that the TLO makes a take-it-or-leave it offer to the firm. Instead of doing so, we assume that the firm has enough bargaining power to obtain the set of continuation payments that maximizes its expected profit. The TLO then bargains with the firm over the size of the upfront fee. If we assume that the firm and the TLO engage in Nash bargaining with threat points equal to zero, then the size of the upfront fee is equal to the bargaining power of the TLO times the firm's profit (gross of the fee, but net of continuation payments.) It follows that the level of continuation payments is the solution to the firm's expected profit maximization problem. This approach is in line with the survey data we use in the empirical analysis. In the survey, we asked businesses to rate the importance of payment types depending on various characteristics of the licensed technology.

Consider a contract $O=\{F, M, r, t\}$. For now, suppose that $r=0$ in all contracts. ${ }^{7}$

commercialization stage, the distinction between the two different types of royalties is inconsequential.

${ }^{7}$ It is straightforward to show that when all three players are risk neutral, for every contract with 
This implies the firm earns $\pi$ from commercializing. Following technical success, it will be willing to invest $C$ in commercial development if and only if the equity payment is not too high. Specifically, $t$ must be such that $z(1-t) \pi-C \geq 0$, which implies $t<\hat{t} \equiv 1-\frac{C}{z \pi}$. With $t<\hat{t}$ and for given $e$, the firm's expected payoff if it invests $X$ in technical development is given by

$$
p(e, X)(z \pi-C-z t \pi-M)-X-F \text {. }
$$

The inventor's expected utility is given by

$$
(1-\alpha) p(e, X)(z t \pi+M)-V(e)
$$

It is clear that for both the firm and the inventor, incentives to invest depend only on the sum of continuation payments and not on each payment type separately. Thus we introduce the notation $S \equiv z t \pi+M$.

\subsection{Optimal inventor effort and optimal level of continuation payments}

Given the contract $O$, the inventor will choose his effort so as to maximize his expected utility. Using $p(e, X)=$ and $V(e)=\exp (e)$ and solving the inventor's expected utility maximization problem, we obtain $e^{*}=\frac{1}{2} \ln (p b \alpha S)$.

We note the following regarding the inventor's optimal level of effort. First, it is clearly increasing in $p$, the baseline probability of technical success. It is also increasing in $b$, the importance of the inventor's role, in $\alpha$, the inventor's share of revenue, and of course in $S$, the sum of continuation payments. Second, note that although we have ruled out output royalties, if such a royalty was part of the contract, it would generate royalty revenue equal to $r x^{*}(r)$. In this case, the inventor's optimal effort level would be equal to $e^{* *}=\frac{1}{2} \ln \left[p b \alpha\left(S+z r x^{*}(r)\right)\right]$. Hence, royalty revenue and milestone revenue (for instance) are perfect substitutes in inventor effort. Hence, for every contract with $r>0$, there exists another contract with $r=0$, a higher milestone payment and the same effort level. The contract with $r=0$ would also generate strictly higher firm expected profit since it does not generate an output distortion.

Since we assume the firm chooses the continuation payments so as to maximize its expected profit, with $r=0$, the optimal value of $S, S^{*}$, solves the following:

$$
\text { Maximize } p\left(e^{*}, X\right)(z \pi-C-S)-X-F \text { with respect to } S \text {. }
$$

$r>$, there exists another contract with $r=0$ that raises the same amount of revenue from continuation payments, but leads to higher effort and higher firm profit. 
The first order condition for an interior solution $S^{*}$ simplifies to

$$
\frac{1}{2} p\left(b z \pi-b C+b S^{*}-2 S^{*} \sqrt{p b \alpha S^{*}}\right)=0 .
$$

The objective function is strictly concave as a function of $S$ for $S>0$, thus, there exists a unique solution. If $X$ is low enough, it is optimal for the firm to accept a contract in which continuation payments sum up to $S^{*}$. Otherwise, the firm will reject the TLO's contract. If it is optimal for the firm to accept the license contract, its payoff gross of the upfront fee is equal to $P^{*} \equiv p\left(e^{*}, X\right)\left(z \pi-C-S^{*}\right)-X$. We make the following assumption to simplify the exposition of our results.

Assumption 1: If a contract specifies continuation payments whose expected sum is $S^{*}$, then the firm is willing to pay a positive upfront fee to obtain the license from the TLO under these contract terms. That is, we restrict attention to values of $(p, b, X, \pi, z, C)$ for which $P^{*} \geq 0$.

Although a closed-form solution for $S^{*}$ exists, its equation is not particularly insightful. Under Assumption 1, we derive comparative statics results summarized in Proposition 1 below. The proof appears in the Appendix.

Proposition 1 Assume the TLO, the firm and the inventor are risk neutral. Under Assumption 1, the optimal value of continuation payments is equal to $S^{*}$, with royalty rate set equal to zero. The optimal sum of continuation payments $S^{*}$ increases with the importance of inventor effort, (b), and decreases with the basic probability of success (p). That is, $\frac{d S^{*}}{d b}>0$ and $\frac{d S^{*}}{d p}<0$ hold.

The result that continuation payments increase with $b$, the importance of inventor effort, is not surprising. With risk neutrality, the only purpose of including continuation payments is to provide incentives for inventor effort. The result that the amount of continuation payments decreases with $p$ is not as straightforward. As $p$ increases, two effects work in opposite directions. The need for high inventor effort decreases because the invention is less likely to fail at the technical development stage. This tends to decrease the return from including continuation payments. However, the inventor will also spend more effort for a given level of continuation payment since $e^{*}$ increases with $p$, which tends to increase the return from continuation payments. The unambiguous sign for $\frac{d S}{d p}$ tells us that the first of the two effects always dominates. 


\subsection{Royalties and risk aversion}

If royalties create a deadweight loss, while milestones do not, why do we observe contracts that include both royalties and milestone payments? A natural explanation is risk aversion on the part of the firm (see Bousquet et al., 1998). In our model, the worst state of nature for the firm is one in which the invention is a technical success but commercial success is not realized. In this case, the firm has to pay the fixed fee plus the milestone payment but earns no revenue from the invention. A positive royalty rate will reduce the variance in the distribution of profits across states and so may be optimal.

If the TLO offers a contract with $r>0$ and $M>0$ but $t=0$, then the inventor will optimally choose effort level $e^{* *}=\ln \left[p b \alpha\left(M+z r x^{*}(r)\right)\right]$, where $r x^{*}(r)$ is royalty revenue. Suppose that the firm is risk averse and has von Neumann-Morgenstern utility function over profit given by $U_{f}(w)$. Under our assumption that the firm has sufficient bargaining power to obtain the continuation payments that maximize its expected payoff, and that the TLO and the firm bargain over the size of the upfront fee, the firm will choose $r$ and $M$ that solve

$$
\text { Maximize } p\left(e^{* *}, X\right)\left[z U_{f}\left(P_{1}\right)+(1-z) U_{f}\left(P_{2}\right)\right]+\left(1-p\left(e^{* *}, X\right)\right) U_{f}\left(P_{3}\right) \text {. }
$$

with respect to $M$ and $r$, where $\left.P_{1}=\left[\pi\left[x^{*}(r)\right]-r x^{*}(r)\right]-C-M\right)-X-F, P_{2}=$ $-C-M-X-F$, and $P_{3}=-F$. In the Appendix, we prove the following proposition.

Proposition 2 Assume the TLO and the inventor are risk neutral, but the firm is risk averse. Also assume that equity contracts are not feasible $(t=0)$. Then, if an optimal contract exists, it must include both a positive royalty rate and a positive milestone payment, $r>0$ and $M>0$.

Therefore, according to Proposition 2, when the firm is risk averse, but the TLO and the inventor are risk neutral, a positive royalty rate, milestone and an upfront fee may coexist. It is straightforward to show that the positive risk spreading effect of royalties is more pronounced the lower $z$ is. Therefore, technologies for which commercialization is highly improbable are those for which royalties are important from the licensee's standpoint.

\subsection{The role of consulting}

The contracts offered by the TLO are constrained because a given share $\alpha$ of revenue must be allocated to the inventor. Consider then a consulting contract between the firm and the inventor, whereby the inventor receives the full consulting fee in the 
contract. Suppose that after the firm has accepted the TLO's contract, but before it and the inventor invest in further technical development, the firm can offer a consulting contract to the inventor.

Assume again that all players are risk neutral. To keep things simple, and show that a consulting contract may be profitable, we assume that the original contract consists of the upfront fee negotiated by the TLO and the firm, as well as the set of continuation payments whose sum equals $S^{*}$ as defined in Section 3.2. Consulting does not make effort fully observable. However, it allows the firm to monitor the inventor. Hence, we assume that a consulting contract consists of a required effort level, $e^{c}$, and a payment, $K$, to the inventor. The firm monitors the inventor's effort and, with probability $m$, observes the actual effort spent. If monitoring reveals that $e<e^{c}$, then the inventor does not receive $K$. In all other cases, the inventor receives $K$. The consulting contract will be profitable only if $e^{c}>e^{*}$.

Suppose the inventor accepts the firm's consulting offer and decides to expand effort level $e=e^{c}>e^{*}$. Then, his expected payoff is equal to

$$
p\left(e^{c}, X\right)(1-\alpha) S^{*}+K-V\left(e^{c}\right) .
$$

On the other hand, if the inventor's effort is $e^{*}<e^{c}$, his expected payoff is

$$
p\left(e^{*}, X\right)(1-\alpha) S^{*}+(1-m) K-V\left(e^{*}\right) .
$$

Hence,

$$
K \geq \frac{\alpha S^{*}\left(p\left(e^{*}, X\right)-p\left(e^{c}, X\right)\right)-V\left(e^{*}\right)+V\left(e^{c}\right)}{m}=\underline{K},
$$

must hold for the inventor to spend effort $e^{c}$.

Why would the firm benefit from the consulting contract? If the firm does not offer the consulting contract, its expected payoff is equal to

$$
p(e, X)\left(z \pi-C-S^{*}\right)-X \text {. }
$$

with $e=e^{*}$. The fact that $X>0$ implies $z \pi-C-S^{*}>0$. Hence, this payoff function is clearly increasing in $e$ for given $S^{*}$. Thus, if the firm can obtain an effort level $e>e^{*}$ from the inventor, then its payoff will be higher than without the consulting contract. If (2) holds, the firm's payoff with the consulting contract in effect is equal to

$$
p\left(e^{c}, X\right)\left(z \pi-C-S^{*}\right)-K-X .
$$

The optimal consulting contract is $\left(e^{c}, K^{c}\right)$, where $K^{c}=\underline{K}$ and $e^{c}$ maximizes the firm's payoff. The following proposition, whose proof appears in the Appendix, characterizes 
the firm's optimal contract when consulting is feasible.

Proposition 3 Assume the TLO, the firm and the inventor are risk neutral and that Assumption 1 holds. Also assume that consulting contracts between the firm and the inventor are allowed by the University. Then, the firm always offers a consulting contract to the inventor. If $\alpha \leq m$, then the firm's optimal contract is such that $S=0$ and $\underline{K}=\frac{V\left(e^{c}\right)}{m}$. That is, incentives for inventor effort are provided solely by the consulting contract. If $\alpha>m$, then the firm's optimal contract includes $S>0$ and $\underline{K}>0$. That is, incentives for inventor effort are provided both by continuation payments and a consulting contract.

An optimal consulting contract always exists and leads to a higher payoff for the firm. Therefore, it will allow the TLO to obtain a higher upfront fee in the bargaining game because the upfront fee is equal to a share of the firm's expected payoff. It thus follows that if an optimal consulting contract exists, then the TLO will not prevent it, so that will be offered in equilibrium.

\section{Empirical results}

Our theoretical analysis yields the following empirical implications. First, in the context of our model, if the firm is risk neutral, royalties will not be part of an optimal contract since other types of continuation payments provide incentives for inventor effort, but do not create an output distortion. Furthermore, according to Proposition 1, the firm will prefer milestone payments and equity when inventor cooperation is needed ( $b$ is high). Interpreting $p$ as a measure of the difficulty of reaching technical success, the less difficult technical development is, the less important continuation payments like milestone payments and equity are.

Proposition 2 yields empirical implications pertaining to the risk involved in developing the technology. When firms are risk averse, output royalties are an important component of contracts if there is a high level of uncertainty at the commercialization stage and equity deals are not feasible. On the other hand, even with firm risk aversion, when commercialization occurs with certainty conditional on the invention being a technical success $(z=1)$, then output royalties are not optimal from the firm's point of view. Proposition 2 also implies that milestone payments may also serve as a risk sharing device at the technical development stage. Hence, other things constant, risk averse firms will find milestone payments important when they license in early stage inventions.

Finally, according to Proposition 3, consulting contracts are always feasible because they allow the firm to request more effort from the inventor, which increases the surplus 
from investing in development by an amount that exceeds the additional effort cost. The profitability of a consulting agreement increases as the probability that the firm can successfully monitor the inventor's effort $(m)$ increases. Hence, it is more likely that consulting contracts will be observed in contexts where it is easier for the firm to monitor the inventor.

\subsection{Inventor moral hazard, risk, and payment types}

To provide information on business attitudes toward risk and payment types, we asked respondents the importance to them of different payment types for early stage technologies and late stage technologies. To provide information on business attitudes toward inventor cooperation, we asked the importance to them of different payment types when faculty input is critical and when it is not critical. ${ }^{8}$ The questions are given in Table 2. Immediately below each question respondents were asked to indicate using a 5 point Likert scale from 5 (extremely important) to 1 (not important) the importance of several payment types including royalties, milestones and equity. Thus, for each of the four questions in Table 2 we have the importance attached to each of three payment types. That is, each respondent could provide up to 12 answers: the importance of each of three payments types for each of four technology characteristics. Out of 112 respondents to the survey, 91 answered at least some of the questions (58\% provided at least one answer to each question), but not all respondents noted the importance of each of the payment types. ${ }^{9}$ Overall, royalties are always more important than the other payment types, this is followed by milestone payments and then equity. The average given by respondents regarding the importance of royalties is 3.7 while importance for milestones and equity is 2.9 , and 1.7 , respectively.

To examine the relative importance of payment types in the circumstances outlined in the questions in Table 2, we consider three regressions in which the dependent variable is the importance a respondent attaches to a particular payment type (royalties, milestone payments, equity) as a function of a set of dummy variables that indicate the question being answered (early stage technology, late stage technology, faculty are critical, faculty are not critical). The equations we estimate are of the form

$R_{i p}=\beta_{0 p}+\beta_{1 p} E A R L Y_{i p}+\beta_{3 p} C R I T_{i p}+\beta_{4 p} N O T C R I T_{i p}+\varepsilon_{i p}, i=1, \ldots, n, p=1, \ldots, 3$.

\footnotetext{
${ }^{8}$ The intent here was to discern business attitudes. Thus alternative measures such as the portion of contracts with various payment types would not be useful since it is an equilibrium result and hence also reflect university attitudes and negotiation.

${ }^{9} \mathrm{It}$ is not surprising that many respondents left blank answers for some questions. For example, if a firm has never used faculty in further development, then they would be unable to answer questions regarding the importance of payment types when faculty are critical and when faculty are not critical.
} 
$R_{i p}$ is the importance attached by individual $i$ to payment type $p, E A R L Y_{i p}=1$ if the question is the one where the technology is in an early stage (0 otherwise), $C R I T_{i p}=1$ if the question is the one where the technology is one for which faculty input is critical (0 otherwise), and NOTCRIT $i p=1$ if the question is the one where faculty input is not critical (0 otherwise). The omitted category is the case where the question is about late stage technologies. These equations take a particular payment type (e.g., royalties) and then consider responses across the four questions listed in Table 2.

Since the responses are ordinal from 5, extremely important, to 1, not important, we use an ordered probit estimator. With each respondent appearing in each equation up to four times (that is, we have a panel of data) we use a fixed effects estimator to control for unobserved heterogeneity across respondents. We consider both heteroschedastic consistent (robust) estimates and estimates that are corrected for a specific form of heteroscedasticity. Regression results for payment type are in Table 3. Part A presents the robust ordered probit coefficients along with $t$ statistics and an indication of the level of significance. Below each regression are chi-square statistics in tests for equality of the coefficients. In Part B are weighted least squares estimates where the weights are the square root of the number of university licenses executed in the year prior to the the survey. ${ }^{10}$ Respondents who execute more licenses should have a clearer idea of relative importance of payment types so that their responses should be subject to less noise. Results for the estimators are very similar.

The results for milestones are clear: they are most important when faculty are critical, this is followed by early stage inventions, then late stage inventions (the omitted category) which are not significantly different from faculty not critical. The importance of milestones when faculty are critical supports our argument that milestones serve to mitigate the moral hazard problem. The finding that early stage inventions are next most important supports our theoretical result that milestones serve to share risk, though they can only serve to share technical risk. Moreover, it suggests the negative correlation between the probability of success and stage of development in our data dominates in the effect of risk on the importance of milestones (i.e., $\frac{d S}{d p}<0$ ).

In the equation for royalties, we find that there is no significant difference in responses for the cases where faculty are critical and not critical. This result is consistent with our theoretical results that when milestones are feasible, royalties should not be used to solve the moral hazard problem. Second, royalties are more important for late stage than for early stage technologies. This result is more difficult to interpret because of the negative correlation between the probability of success $z$ and the stage

\footnotetext{
${ }^{10}$ We not only asked for the number of licenses executed in the year prior to the survey but also the number of licenses executed in the five year period prior to the survey. Fewer respondents answered the five year question thus we use the number of licenses in only the prior year. The simple correlation between the the one year and the five year responses is 0.86 .
} 
of development. Even if royalties are not intended to solve the moral hazard problem, if inventor effort is involved the effect of a change in the probability of success on the importance of continuation payments is ambiguous. Furthermore, in the theory, with a risk averse licensee, a lower probability of commercial success $z$ is associated with greater use of royalties. That said, we suspect our empirical result is most likely related to the fact that royalties based on sales are the hardest to define for early stage inventions, an effect that our theoretical model does not capture. ${ }^{11}$ Many university inventions are so embryonic that downstream products cannot be defined at the time of license and many inventions have a variety of applications (Shane, 2000). Thus, in contrast to Bousquet et al's (1998) presumption that milestones may be hard to define, in the case of university licenses, royalties may be more difficult to define. There are therefore two competing effects for royalties: risk sharing which ceteris paribus would be more important for early stage technologies, and the difficulty of determining royalty rates which would make them more important for late stage technologies (which still reflect market risk). Our results suggest that the latter effect dominates.

Finally, the equity equation is weakly supportive of the role of equity in dealing with moral hazard: the only significant relationship (at the 10\% level) is the greater role of equity when faculty are critical versus when faculty are not critical. Our weak results might well follow from the fact that for large, publicly traded companies, equity and cash are essentially equivalent. We considered this regression after dropping large firms, but the results continued to be poor.

\subsection{The role of consulting}

In Section 3.3, we showed that consulting and milestones can both address inventor moral hazard. In our business survey, we asked respondents to indicate the percent of time faculty consulting was used when faculty input is critical for further development. On average, respondents indicated that they used consulting $58.7 \%$ of the time. There was, however, a lot of variation in responses. The standard deviation was $34 \%$ and the range was from $0 \%$ to $100 \%$. Some of this variation, we hypothesize, is a function of the seriousness of the moral hazard problem faced by firms.

Since our measure of consulting is a percent we make a standard adjustment and use the log of the odds ratio (that is, the logit) as the dependent variable. The odds ratio is the fraction of time consulting is used divided by one minus that fraction. ${ }^{12}$ To test for

\footnotetext{
${ }^{11}$ In the university survey, we asked an open ended question about the use of royalties. Thirty three percent said that royalties were always or almost always used except for software or technologies for internal firm use only. The most common reason listed for royalties listed was dealing with risk. As one respondent said "... if we knew how much the invention was going to make for the licensee - in advance - it would be quite reasonable to ask all royalties be paid up front."

${ }^{12}$ Since fracton of consulting can be 0 or 1 we follow Cox's (1970) suggestion and add a small positive
} 
the link between consulting and moral hazard, we regress the percent of time the firm uses consulting on, among other factors, a measure of the moral hazard problem faced - or perceived to be faced - by the firm (MILESTONE_IMPORT). The measure we use for moral hazard is the importance that firms attach to milestone payments when faculty are critical to further development. That is, we use their response to milestones in question 3 in Table 3. If, as the results in the previous section suggest, respondents view milestones as a mechanism for dealing with inventor moral hazard, then we argue the importance of milestone payments is a measure of the respondent's perception of inventor moral hazard faced by the firm. Recall that respondents provide measures of importance ranging from 5 (extremely important) to 1 (not important). In this analysis we do not use the actual responses since respondents likely define levels of importance differently - for example, two respondents might view some payment type for some technology as equally important, but one scores it as a "5" while the other scores it as a "4." To get around this problem we compute the measure of importance as the deviation of a response from the average response a respondent makes to all questions. $^{13}$

Additional regressors include a dummy variable for small firms $(S M A L L)$. Here we define small as firms with fewer than 100 employees. Our reason for including a measure for size is based on discussions with university technology transfer professionals who told us that it is more common for small firms to use consulting as a means for obtaining faculty input.

We also include a variable to measure distance of a firm from the universities from whom they license (DISTANCE). The further a firm is from the faculty inventor, the more difficult is a consulting arrangement. In our survey we asked for the five universities most important in terms of licensing. Our measure of distance is the average distance from the universities listed by each respondent.

The use of consulting may depend, in part, on the stage of development of the technology. To control for stage of development we include the percent of the time that the firm licenses in technologies that are only a proof of concept (PROOF) and the percent of time that they license in technologies for which there is only a lab scale prototype (PROTOTYPE). These are the two earliest stages for licensed in technologies.

Finally, firms may also use sponsored research to obtain faculty input. In our

number to both the numerator and denominator of the odds ratio. This logit regression is known to be heteroscedastic (see, for example, Maddala, 1983). Unfortunately, both the optimal small number to add to consulting and the weights to correct for heteroscedascity require information we do not have. To deal with the heteroscedascity we use robust standard errors.

${ }^{13}$ We do not need to make this adjustment for the econometric models considered earlier since a fixed effects model is used. 
survey we not only asked about the percent of time that consulting was used but also the percent of time sponsored research was used when faculty are critical. On average respondents indicated that they used sponsored research $43.1 \%$ of the time when faculty are critical. Our final variable is the percent of time sponsored research is used (SPON_RESEARCH). Sponsored research and consulting, while not mutually exclusive, are very likely to be simultaneously determined; the more one is used the less one would expect the other to be used. The simple correlation is -0.33 . For that reason we use two-stage least squares (with robust standard errors). The instrument we use for sponsored research is the percent of in-house research conducted by the firm that is basic. In Thursby and Thursby (2004) we find a significant and positive relationship between sponsored research and in-house basic research. In the limit, the amount of basic research should be correlated with the amount of sponsored research and uncorrelated with the disturbance.

In Table 4 are summary statistics for the 36 observations for which we have observations on all variables. Table 5 presents the econometric results. Robust standard errors are used and results are in terms of the odds ratio. An odds ratio value less than one indicates that an increase in the independent variable reduces the level of consulting. In the first panel we include all regressors. PROOF has a t-statistic of only -0.25 . In the second panel it is omitted. In spite of having only 36 observations for which all data are available, we are nonetheless able to uncover significant relationships. As expected sponsored research and consulting are negatively and statistically significantly ( $5 \%$ level) related in both panels. Also, and as expected, the greater the distance between the firm and universities the less likely are consulting arrangements (statistically significant at the $5 \%$ level). Small firms are more likely to use consulting in accordance with our interviews with technology transfer professionals; however, the coefficient is not significant at conventional levels. The higher the percent of licensedin technologies that are only a lab scale prototype (PROTOTY PE) the more likely the firm will use consulting, but the coefficient is not significantly different from zero. Finally, the coefficient of the importance attached to milestone payments when faculty are critical is positive and significant ( $5 \%$ level) which we argue shows that the more serious the moral hazard problem faced by the firm, the more likely it is to observe consulting contracts.

\section{Conclusion}

University-industry technology transfer is an important part of national innovation systems and one fraught with incentive problems, largely because of the embryonic nature of most university inventions. In this paper, we focus on the role of contracts, 
and in particular the form of payment in overcoming the distortions introduced by the need for inventor effort. Our theoretical and empirical results suggest that milestones are prevalent because of inventor moral hazard. Royalties are not used to address moral hazard and the risk sharing role of royalties is mitigated by difficulties in defining them for early stage inventions. They also suggest that consulting as a part of license contracts is related to inventor moral hazard.

It is the university ownership of the invention that makes our contracting problems fundamentally different from those of Aghion and Tirole (1994). In our model the researcher (inventor) has a moral hazard problem that does not exist in their framework where either the researcher or the customer (licensee in our case) owns the invention. However, it is well understood from principal-agent theory that if the agent is risk neutral and faces no limited liability constraints, the principal can usually fully solve the moral hazard problem by "selling" the project to the agent and extracting rent with a fixed fee (see, for instance, Laffont, 1989). This solution is reminiscent of a commonly observed practice in university licensing, which consists of letting the inventor start up her own firm to develop and commercialize the invention. An interesting question for further research, particularly given increasing commercialization through inventor startup companies, is when it would be optimal for the university to transfer ownership to the inventor. This question has also been the topic of debate among a number of European countries where traditionally ownership has resided with the inventor (OECD 2003). Another question, currently a point of contention between some firms and universities, is when the firm funds the research, whether firm ownership is optimal.

\section{References}

\section{References}

[1] Aghion, Philippe and Tirole, Jean. 1994. "The Management of Innovation," Quarterly Journal of Economics, 109, pp. 1185-1209.

[2] Agrawal, Ajay. 2006. "Engaging the Inventor: Exploring Licensing Strategies for University Inventions and the Role of Latent Knowledge," Strategic Management Journal 27, 63-79.

[3] Anand, Bharat and Khanna, Tarun. 2000. "The Structure of Licensing Contracts," The Journal of Industrial Economics 48, pp.103-135. 
[4] Arora, Ashish, Fosfuri, Andrea, and Gambardella, Alfonso. 2001. Markets for Technology: The Economics of Innovation and Corporate Strategy. Cambridge, MA: MIT Press.

[5] Beath, J., Owen, R., Poyago-Theotoky, J., Ulph, D., 2003. Optimal incentives for income-generation within universities. International Journal of Industrial Organization 21, 1301-1322

[6] Bousquet, Alain, Cremer, Helmuth, Ivaldi, Marc, and Wolkowiz, Michel. 1998. "Risk Sharing in Licensing." International Journal of Industrial Organization 16, pp. 535-554.

[7] Caves, Richard E., Crookell, Harold and Killing, J. Peter. 1983. "The Imperfect Market for Technology Licenses." Oxford Bulletin of Economics and Statistics 45, pp. 249-268.

[8] Choi,J.P. 2001. "Technology Transfer with Moral Hazard," International Journal of Industrial Organization 19, pp. 249-266.

[9] Cohen, Wesley M., Florida, Richard, Randazzese, L. and Walsh, John. 1998. "Industry and the Academy: Uneasy partners in the cause of technological advance." in Roger Noll, editor, Challenges to US Research Universities. The Brookings Institution, Washington, D.C.

[10] Colyvas, Jeannette, Michael Crow, Annetine Gelijns, Roberto Maxxoleni, Richard Nelson, Nathan Rosenberg, and Bhaven Sampat. 2002. How do University Inventions Get into Practice? Management Science, 48:1, 61-72.

[11] Cox, D.R. 1970. Analysis of Binary Data. London: Methuen.

[12] Dasgupta, P. and David, P. 1994. Toward a New Economics of Science. Research Policy, 23, 486-521.

[13] Dechenaux, Emmanuel, Thursby, Marie, and Thursby, Jerry. 2008. "Shirking, Sharing-Risk, and Shelving: The Role of University Contracts," mimeo.

[14] Edwards, Mark G., Murray, Fiona, and Yu, Robert. 2003. "Value Creation and Sharing Among Universities, Biotechnology and Pharma," Nature Biotechnology, 21(6), pp. 618-624.

[15] Elfenbein, Dan. 2004. "Contract Structure and Performance of Technology Transfer Agreements: Evidence from University Licenses," mimeo. 
[16] Feldman, Maryann, Feller, Irwin, Bercovitz, Janet, and Burton, Richard. 2001. "Equity and the Technology Transfer Strategies of American Research Universities," Management Science 48 (1), pp. 105-121.

[17] Jensen, Richard and Thursby, Marie C. 2001. "Proofs and Prototypes for Sale: The Licensing of University Inventions," American Economic Review 91(1), pp. 240-259.

[18] Jensen, Richard, Thursby, Jerry G., and Thursby, Marie C.2008. "In or Out: Faculty Research and Consulting, mimeo.

[19] Lach, Saul, and Schankerman, Mark. 2008. "Incentives and Invention in Universities," Rand Journal of Economics, forthcoming.

[20] Laffont, Jean Jacques. 1989. The Economics of Uncertainty and Information. Cambridge, MA: The MIT Press.

[21] Levin, Sharon and Paula Stephan. 1991. "Research Productivity over the Life Cycle: Evidence for Academic Scientists." American Economic Review. 81:1, 114132 .

[22] Macho-Stadler, Ines Martinez-Giralt, Xavier and Castrillo-Perez, J. David. 1996. "The Role of Information in Licensing Contract Design." Research Policy (25), pp. $43-57$.

[23] Maddala, G.S. 1983. Limited-Dependent and Qualitative Variables in Econometrics. New York: Cambridge University Press.

[24] Mansfield, E. 1995. "Academic research underlying industrial innovations: sources, characteristics, and financing." The Review of Economics and Statistics, $77,55-65$.

[25] Rostoker, M.D., 1983. "A Survey of Corporate Licensing," The Journal of Law and Technology 24, pp. 59-92.

[26] Shane, Scott. 2000. "Prior Knowledge and Discovery of Entrepreneurial Opportunities," Organizational Science, pp. 448-469.

[27] Taylor, C. T. and Silberston, Z. A. 1973. The Economic Impact of the Patent System: A Study of the British Experience. Cambridge: Cambridge University Press. 
[28] Thursby, Jerry, Jensen, Richard, and Thursby, Marie. 2001. "Objectives, Characteristics and Outcomes of University Licensing: A Survey of Major U.S. Universities," Journal of Technology Transfer, 2001, 26, 59-72.

[29] Thursby, Jerry and Thursby, Marie. 2002. "Who is Selling the Ivory Tower? Sources of Growth in University Licensing," Management Science 48(1), pp. 90104.

[30] Thursby, Jerry and Thursby, Marie. 2003. "University Licensing and the BayhDole Act," Science, 301, p. 1052.

[31] Thursby, Jerry and Thursby, Marie.2004. "Are Faculty Critical? Their Role in University Licensing," Contemporary Economic Policy 22(2), 162-178.

[32] Thursby, Jerry G., Fuller, Anne, and Thursby, Marie C. 2007. US Faculty Patenting: Inside or Outside the University, mimeo.

[33] Thursby, Marie, Jerry Thursby and Swasti Gupta-Mukherjee. 2007. Are There Real Effects of Licensing on Academic Research? A Life Cycle View. Journal of Economic Behavior \& Organization 63, August 2007, 577-598.

[34] Thursby, Jerry and Thursby, Marie. 2008. "Knowledge Creation and Diffusion of Public Science with Intellectual Property Rights," Intellectual Property Rights and Technical Change, Frontiers in Economics, Vol. 2, edited by Keith Maskus, Elsevier, forthcoming. 


\section{Appendix A: Proofs}

\subsection{Proposition 1}

To show that a risk neutral firm would never request a positive royalty rate from risk neutral TLO and inventor, note that in $e^{* *}, r$ and $M$ act as perfect substitutes. Hence, for every $r>0$, there exists an $M^{\prime}$ such that a contract with $r^{\prime}=0$ and $M^{\prime}=0$ yields the same effort level as a contract with $r>0$ and $M \geq 0$. Since the milestone payment does not create a deadweight loss, while the output royalty does, the contract with $r^{\prime}=0$ and $M^{\prime}>0$ yields a greater expected revenue to the firm. Hence, in the remainder of the proof, we set $r=0$.

The optimal value of $S$, the sum of continuation payment, is the solution to (3.1) subject to the constraints $S \geq 0$ and $p(e, X)(z \pi-C-S)-X \geq 0$. Ignoring this last constraint, it is straightforward to show that the first order condition for an interior solution simplifies to (1). Straightforward calculations yield that for $S>0$, the second derivative of the objective function is equal to $-\frac{3 z \pi-3 C+S}{4 S^{2} \sqrt{p b \alpha S}}<0$. Hence, there exists a unique solution $S^{*}$.

Now, assume that Assumption 1 holds. We apply the implicit function theorem to equation (1). After simplifying, we obtain:

$$
\frac{d S}{d p}=\frac{S[b(z \pi-C+S)-4 S \sqrt{p b \alpha S}]}{p b(3 z \pi-3 C+S)}<0,
$$

and

$$
\frac{d S}{d b}=\frac{S(z \pi-C+S)}{b(3 z \pi-3 C+S)}>0
$$

Since $z \pi-C-S>0$, then, unambiguously, $\frac{d S}{d b}>0$. That $\frac{d S}{d p}<0$ follows from the fact that the denominator is positive, while using the first order condition (1), it is clear that the numerator is negative.

\subsection{Proposition 2}

To show that the royalty rate will be strictly positive in the contract that is optimal for the firm, suppose that there exists $M>0$ and $F>0$ such that the firm would accept the contract $O=(F, M)$ with $r=0$ and invest $X$. Since equity contracts are not feasible, $S=M$ and the inventor's effort is equal to $e^{* *}$ (with $r=0$ ). Now, consider a simultaneous marginal increase in $r$ from $r=0$ and a simultaneous marginal decrease in $M$ that keeps the inventor's effort constant at $e^{* *}$. That is, consider changes $d r$ and $d M$ such that $z x(0) d r=-d M$. If $U_{f}$ is strictly concave, this will increase the firm's expected payoff for $z<1$. Indeed, setting $r=0$, the small increase in royalty 
combined with the decrease in milestone payment has the following effect on the firm's expected payoff:

$$
d\left[E U_{f}\right]=p\left(e^{* *}, X\right)\left[(1-z) U_{f}^{\prime}\left(P_{2}\right)(-d M)+z U_{f}^{\prime}\left(P_{1}\right)(-x(0) d r-d M)\right] .
$$

Using $z x(0) d r=-d M$ and re-arranging the above expression, we find that the change in expected utility is strictly positive if and only if $U_{f}$ is strictly concave.

We now show that if the firm is willing to accept a contract $O=(F, M, r)$, with $r>0$ and $M=0$, then there exists a contract with $M>0$ that leads to a strictly higher expected profit. Hence, the firm will prefer a contract with $M>0$. Note that with contract $O$, the inventor spends effort $e^{* *}$ (with $M=0$ ).

The firm's expected payoff is equal to

$$
p\left(e^{* *}, X\right)\left[z U_{f}\left(P_{1}\right)+(1-z) U_{f}\left(P_{3}\right)\right]+\left(1-p\left(e^{* *}, X\right)\right) U_{f}\left(P_{3}\right) .
$$

where $\left.P_{1}=\left[\pi\left[x^{*}(r)\right]-r x^{*}(r)\right]-C\right)-X-F$ and $P_{3}=-F$.

Now consider marginal changes in $F$ and $M$ that keep licensing revenue constant. That is consider $d M$ and $d F$ such that $\left[p^{\prime}(e, X) \frac{\partial e}{\partial M} M+p(e, X)\right] d M=-d F$ or, in the limit as $M$ goes to zero, $p\left(e^{* *}, X\right) d M=-d F$, where $d F<0$ and $d M>0$. We show that this change will lead to a higher expected payoff for the firm.

Again, in the limit as $M$ is close to zero, the total effect on the firm's expected payoff is equal to

$$
\begin{array}{r}
p^{\prime}\left(e^{* *}, X\right) \frac{\partial e^{* *}}{\partial M}\left[z U_{f}\left(P_{1}\right)+(1-z) U_{f}\left(P_{3}\right)-U_{f}\left(P_{3}\right)\right] d M+ \\
-p\left(e^{* *}, X\right)\left[z U_{f}^{\prime}\left(P_{1}\right)-(1-z) U_{f}^{\prime}\left(P_{3}\right)\right] d M- \\
\left.p\left(e^{* *}, X\right)\left[z U_{f}^{\prime}\left(P_{1}\right)-(1-z) U_{f}^{\prime}\left(P_{3}\right)\right] d F-\left(1-p\left(e^{* *}, X\right)\right) U_{f}^{\prime}\left(P_{3}\right)\right] d F .
\end{array}
$$

Using the fact that $p\left(e^{* *}, X\right) d M=-d F$ and rearranging, we obtain

$$
\begin{aligned}
& p^{\prime}\left(e^{* *}, X\right) \frac{\partial e^{* *}}{\partial M}\left[z\left(U_{f}\left(P_{1}\right)-U_{f}\left(P_{3}\right)\right)\right] d M+ \\
& \left(1-p\left(e^{* *}, X\right)\right) z\left[U_{f}^{\prime}\left(P_{1}\right)-U_{f}^{\prime}\left(P_{3}\right)\right] d F>0 .
\end{aligned}
$$

The strict inequality follows from $U_{f}\left(P_{1}\right)>U_{f}\left(P_{3}\right)$ because $U_{f}$ is increasing, $d M>0$, $U_{f}^{\prime}\left(P_{1}\right)<U_{f}^{\prime}\left(P_{3}\right)$ because $U_{f}$ is strictly concave, and $d F<0$.

\subsection{Proposition 3}

In this section we prove Proposition 3 by characterizing the optimal consulting contract for all values of $\alpha$ and $m$. To this effect, note that if the firm offers a consulting contract, 
given the chosen $e^{c}$, it will set $K=\underline{K}$. The optimal combination of continuation payments and consulting contract maximizes the firm's expected payoff

$$
p\left(e^{c}, X\right)\left(z \pi-C-S^{*}\right)-\underline{K}-X
$$

with respect to $e^{c}$ and $S$. Differentiating the firm's expected payoff with respect to $e^{c}$ and $S$, we obtain the following expressions.

$$
\begin{gathered}
p^{\prime}\left(e^{c}\right)(z \pi-C-S)+\frac{p^{\prime}\left(e^{c}\right) \alpha S-V^{\prime}\left(e^{c}\right)}{m}, \\
\frac{\alpha-m}{m} p^{\prime}\left(e^{c}\right)-\frac{\alpha}{m} p\left(e^{*}\right) .
\end{gathered}
$$

We first show that if a solution exists, then $e^{c}>e^{*}$ holds. To this effect, note that for every $S$, the first term in 6 is strictly positive, while the second term vanishes in the limit as $e^{c}$ goes to $e^{*}$. That is because $e^{*}$ maximizes the inventor's expected payoff. Hence, if $e^{c}=e^{*},(6)$ is strictly positive, which implies that the firm could increase its payoff by increasing $e^{c}$.

Assume $\alpha<m$. Since if a solution exists, $e^{c}>e^{*}$, in this case, it is straightforward to see that (7) is strictly negative. It follows that the firm will set $S=0$. The optimal value of $e^{c}$ is the solution of (6) set equal to zero. Setting $S=0$ and differentiating (6) yields $p^{\prime \prime}\left(e^{c}\right)(z \pi-C)-\frac{V^{\prime \prime}\left(e^{c}\right)}{m}<0$. Therefore, the second order condition is satisfied. Finally, because $S=0$, it follows that $\underline{K}=\frac{V\left(e^{c}\right)}{m}$.

Now assume $\alpha>m$. From $e^{c}>e^{*}$, at $S=0,(7)$ is equal to $\left(\frac{\alpha}{m}-1\right) p\left(e^{c}\right)>0$ so that for every $e^{c}$, the firm can increase its expected payoff by increasing $S$ above 0 . We therefore look for an interior solution, where $e^{c}>e^{*}$ and $S>0$. At such a solution, both (6) and (7) are equal to zero. To show that a solution exists, we use the functional forms given in the text and solve the system of equations for $e^{c}$ and $S$ (recalling the expression for $e^{*}$ ). We obtain a unique solution.

We now show that the second order conditions hold. The Jacobian of the system formed by (6) and (7) is

$$
\left[\begin{array}{ll}
A_{1} & B_{2} \\
A_{2} & B_{1}
\end{array}\right]
$$

where $A_{1}=p^{\prime \prime}\left(e^{c}\right)(z \pi-C-S)+\frac{p^{\prime \prime}\left(e^{c}\right) \alpha S-V^{\prime \prime}\left(e^{c}\right)}{m}<0, B_{1}=0, A_{2}=\frac{\alpha-m}{m} p^{\prime}\left(e^{c}\right)>0$, and $B_{2}=\frac{\alpha-m}{m} p^{\prime \prime}\left(e^{c}\right)<0$. Since $A_{1}<0$ and $A_{1} B_{1}-A_{2} B_{2}>0$, the SOC holds.

Finally, assume $\alpha=m$. In this case, (7) is equal to zero at $S=0$. However, because $e^{c}>e^{*}$ and $p(e)$ is strictly concave, $(7)$ is strictly decreasing at $S=0$ for all $e^{c}$. Therefore, the TLO will set $S=0$. 


\section{Appendix B: Survey Data}

The business survey was designed to be answered by individuals actively engaged in executing licenses, options, and/or sponsored research agreements with universities between 1993-1997. We received responses from 112 business units that had licensed-in university inventions. Firms in our sample accounted for at least $15 \%$ of the license agreements and 17\% of sponsored research agreements reported by AUTM in 1997. Seventy-nine firms in the sample responded to a question on the top five universities with whom they had contractual agreements. The 85 universities mentioned include 35 of the top 50 universities in terms of industry sponsored research and 40 of the top 50 licensing universities in the 1997 AUTM Survey. The majority of respondents were employed by small firms, with $46 \%$ answering for firms with less than one-hundred employees and $17 \%$ for firms with more than one hundred but less than five hundred employees. In terms of industry segments, $31 \%$ of the respondents identified pharmaceuticals as the main industry in which their firm operated, 36\% indicated biotechnology and medical devices as their main industry, and 33\% indicated other industries. $91 \%$ of the sample conducted some R\&D in-house. On average, $37 \%$ of the R\&D conducted in-house was basic or discovery research, $44 \%$ was new product development, and $18 \%$ was process improvement. Finally, many of the firms in the business survey are not publicly traded, which precludes the usual tests for selectivity bias. As reported in Thursby and Thursby (2004), we used an alternative approach of comparing data on respondents with that of the general population reported in the AUTM survey as well as our earlier university survey. Other details of survey design can be found in Thursby and Thursby $(2001,2003)$. 


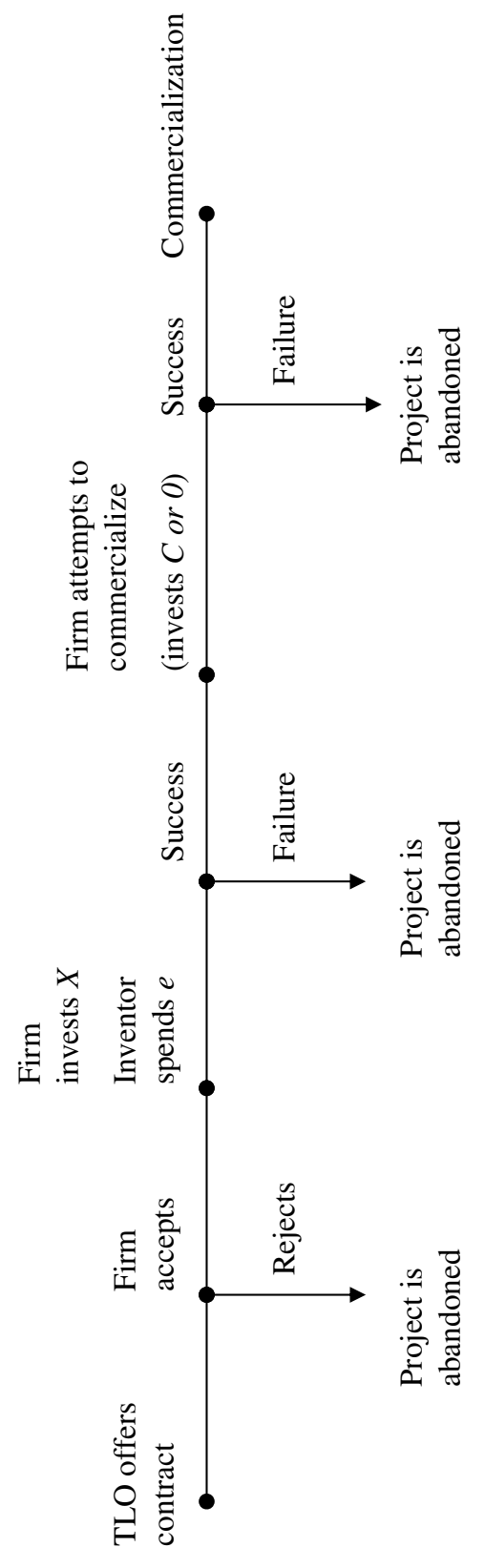

Figure 1: Timeline of decisions. 


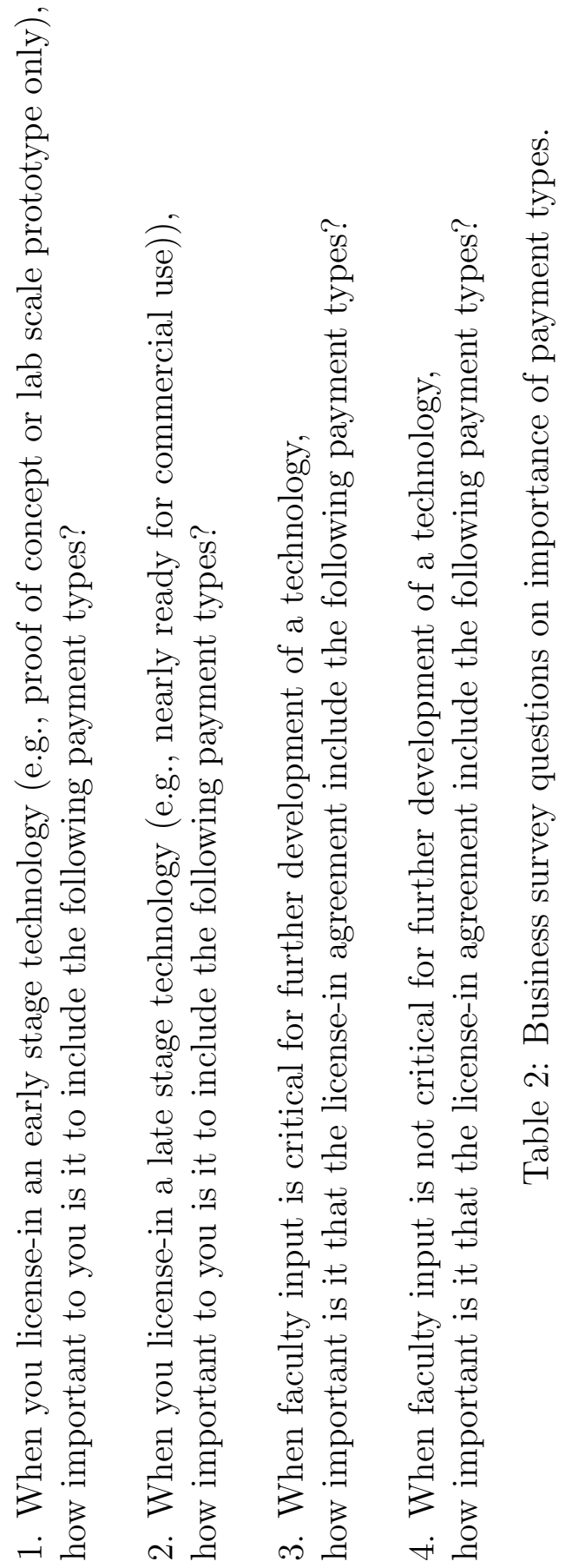



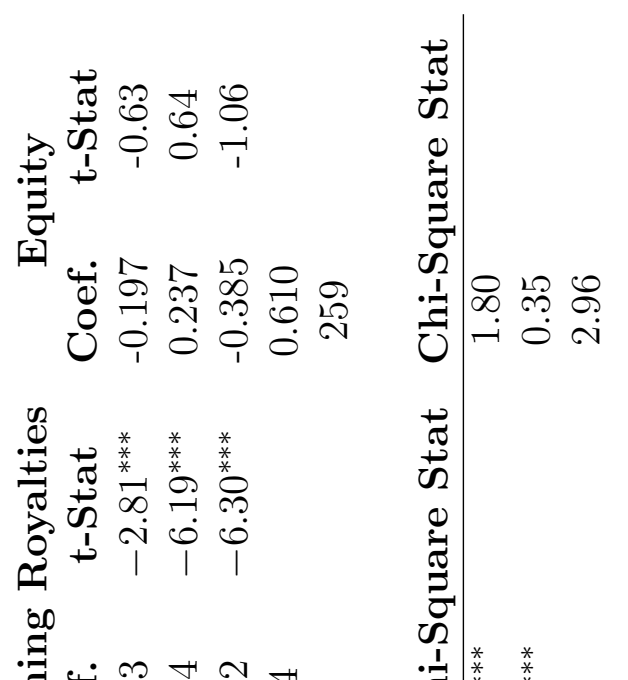

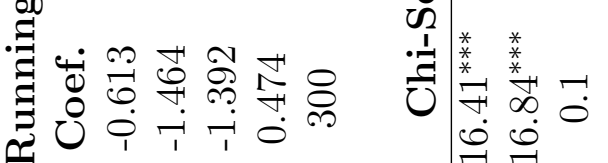
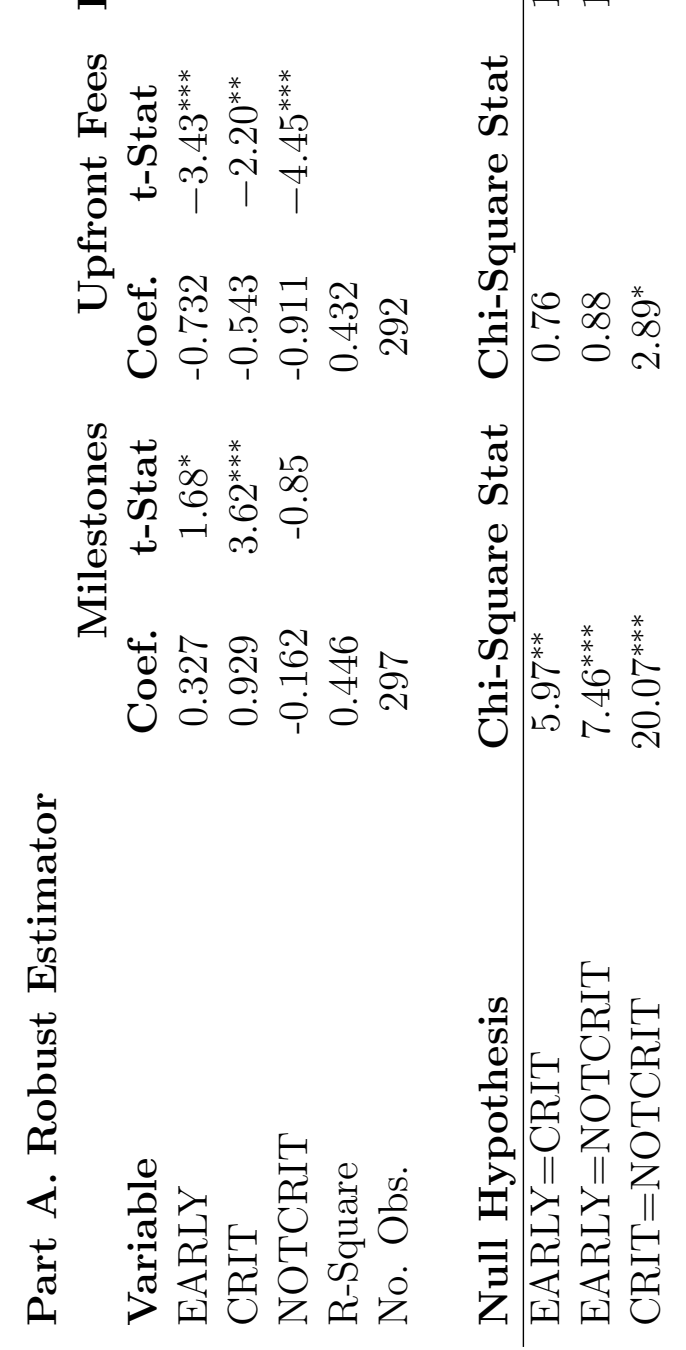

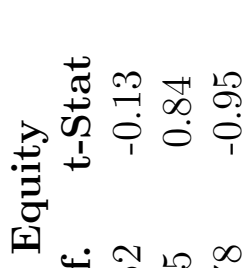

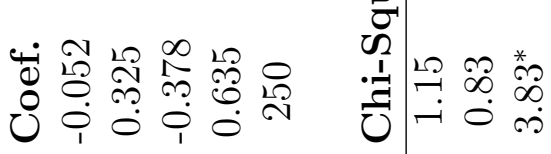

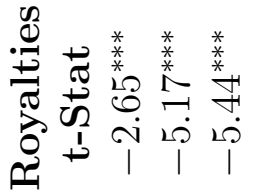

$\infty$

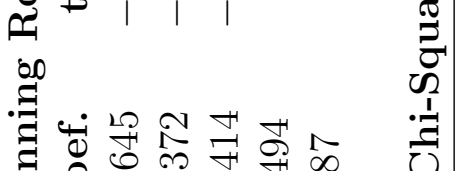
J

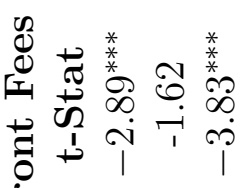
है

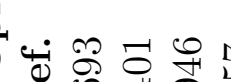

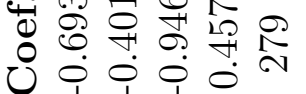

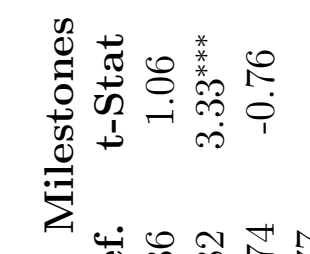

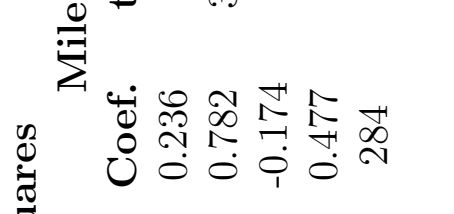

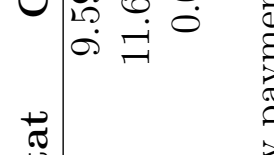

$\stackrel{\dot{0}}{0}$

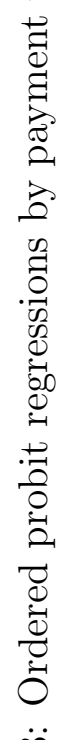

苦的
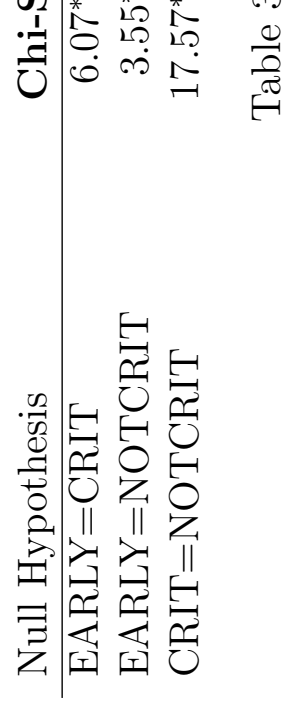


$\begin{array}{lccc}\text { Variable } & \text { Mean } & \text { Min } & \text { Max } \\ \text { SMALL } & 0.39 & 0 & 1 \\ \text { CONSULTING } & 59.31 & 0 & 100 \\ \text { DISTANCE } & 788.24 & 6 & 1770 \\ \text { MILESTONE_IMPORT* }^{*} & 3.39 & 1 & 5 \\ \text { PROOF } & 34.31 & 0 & 100 \\ \text { PROTOTYPE } & 40.83 & 0 & 100 \\ \text { SPON_RESEARCH } & 43.11 & 0 & 100\end{array}$

Table 4: Summary Statistics. Regressions are based on deviations from individual means.

$\begin{array}{lcccc}\text { Variable } & \text { Odds ratio } & \text { t-Stat } & \text { Odds } & \text { t-Stat } \\ \text { SPON_RESEARCH } & 0.884 & -2.10^{*} & 0.878 & -2.43^{*} \\ \text { DISTANCE } & 0.996 & -2.24^{*} & 0.996 & -2.10^{*} \\ \text { MILESTONE_IMPORT } & 8.236 & 2.42^{*} & 8.484 & 2.40^{*} \\ \text { SMALL } & 28.263 & 1.55 & 29.492 & 1.54 \\ \text { PROOF } & 0.994 & -0.25 & & \\ \text { PROTOTYPE } & 1.027 & 0.74 & 1.032 & 1.05 \\ \text { No. Observations } & 36 & & 36 & \\ \text { R-Square } & 0.304 & & 0.247 & \\ \text { * Significant at } 5 \% & & & & \end{array}$

Table 5: Instrumental Variables Results for Consulting. 